\title{
Herbivores sculpt leaf traits differently in grasslands depending on life form and land-use histories
}

\author{
Jennifer Firn, ${ }^{1,3}$ Martin Schütz, ${ }^{2}$ Hudong Nguyen, ${ }^{1}$ and Anita C. Risch ${ }^{2}$ \\ ${ }^{1}$ School of Earth, Environmental and Biological Sciences, Faculty of Science and Technology, \\ Queensland University of Technology, Brisbane, Queensland 4001 Australia
${ }^{2}$ Swiss Federal Institute for Forest, Snow and Landscape Research (WSL), Zürcherstrasse 111, 8903, Birmensdorf, Switzerland
}

\begin{abstract}
Vertebrate and invertebrate herbivores alter plant communities directly by selectively consuming plant species; and indirectly by inducing morphological and physiological changes to plant traits that provide competitive or survivorship advantages to some life forms over others. Progressively excluding aboveground herbivore communities (ungulates, medium and small sized mammals, invertebrates) over five growing seasons, we explored how leaf morphology (specific leaf area or SLA) and nutrition (nitrogen, carbon, phosphorous, potassium, sodium, and calcium) of different plant life forms (forbs, legumes, grasses, sedges) correlated with their dominance. We experimented in two subalpine grassland types with different landuse histories: (1) heavily grazed, nutrient-rich, short-grass vegetation and (2) lightly grazed, lower nutrient tall-grass vegetation. We found differences in leaf traits between treatments where either all herbivores were excluded or all herbivores were present, showing the importance of considering the impacts of both vertebrates and invertebrates on the leaf traits of plant species. Life forms responses to the progressive exclusion of herbivores were captured by six possible combinations: (1) increased leaf size and resource use efficiency (leaf area/nutrients) where lower nutrient levels are invested in leaf construction, but a reduction in the number of leaves, for example, forbs in both vegetation types, (2) increased leaf size and resource use efficiency, for example, legumes in short grass, (3) increased leaf size but a reduction in the number of leaves, for example, legumes in the tall grass, (4) increased number of leaves produced and increased resource use efficiency, for example, grasses in the short grass, (5) increased resource use efficiency of leaves only, for example, grasses and sedges in the tall grass, and (6) no response in terms of leaf construction or dominance, for example, sedges in the short grass. Although we found multiple possible responses by life forms to progressive exclusion of herbivores, we also found some important generalities. Changes in leaf traits of legumes and grasses correlated with their increasing dominance in the short-grass vegetation and plants were more efficient at constructing photosynthetic tissue when herbivores are present with few exceptions. These results demonstrate that vertebrate and invertebrate herbivores are essential to maintain plant species richness and resource-use efficiency.
\end{abstract}

Key words: herbivore-induced damage on plants; invertebrates; leaf economic spectrum; plant community dynamics; plant-herbivore interactions; resource use efficiency.

\section{INTRODUCTION}

Vertebrate and invertebrate herbivores consume considerable amounts of aboveground biomass (Delting 1998), which directly alters aboveground primary productivity (Milchunas and Lauenroth 1993); and because of feeding preferences, plant community composition (Diaz et al. 2007). Because herbivory is generally a nonlethal cross-trophic-level interaction (unlike predation), most plants will also experience indirect effects of being fed upon that manifest into altered traits, e.g., producing allelopathic chemicals, changing physiology, morphology, growth, and phenology (Utsumi et al. 2010a). However, the consequences of ubiquitous and non-lethal

Manuscript received 28 April 2016; revised 6 September 2016; accepted 26 September 2016. Corresponding Editor: Peter M. Kotanen.

${ }^{3}$ E-mail: jennifer.firn@qut.edu.au interactions of types of herbivores on the success of different plant life forms coexisting in communities is not well studied in both the fields of plant-animal interactions and plant functional traits (Ohgushi 2005).

Part of this lack of focus on identifying the broader implications of herbivore-induced changes on plant communities is the complex set of interactions that are potentially impacted (Ohgushi 2005, Utsumi et al. 2010a, b). Herbivore-induced damage on plants may sculpt plant communities because of differences in feeding habits, selectivity of feeding behavior, the capacity of plants to respond to damage, and the "full circle" response of plant-mediated indirect effects on herbivores including the production of allelopathic chemicals (Denno and Kaplan 2007). These complex herbivore-induced indirect effects invoke a series of "chain reactions" within and across trophic levels that likely have significant implications for species richness and abundance in both plant 
and animal communities (Ohgushi 2005, Utsumi et al. 2013).

Numerous leaf trait studies have discovered "soft" traits that can act as surrogates for more complex physiological processes within plants (Wright et al. 2004, Westoby and Wright 2006). Combinations of these traits or "syndromes" are representative of growth strategies wielded by different plant life forms and species. The leaf economic spectrum proposes a fundamental trade-off in the traits held by fast- and slow-growing plant species (Diaz et al. 2004, Wright et al. 2004, Westoby and Wright 2006). Fastgrowing plant species, also referred to as resource acquisition specialists, are better at resource capture, and generally occupy sites where resources are not limiting. These fast growing species have generally higher specific leaf area (SLA $\left[\mathrm{mm}^{2} / \mathrm{mg}\right.$ ], fresh leaf area [LA]/oven-dry mass), and higher overall leaf nutrient contents. Resource acquisition specialists also are more efficient in their nutrient use, being able to produce a larger SLA with a lower investment of leaf nutrients in the formation of tissue. Slow-growing plant species, also referred to as resource conservation specialists, have a lower rate of return on their investments of photosynthesis and nutrients in the formation of leaf tissue. Resource conservation specialists are generally characterized as conserving resources and to tend to hold opposite traits to resource acquisition specialists: lower SLAs and lower nutrient contents (Diaz et al. 2004, Wright et al. 2004, Westoby and Wright 2006).

Studies have found that these soft leaf traits can be used to monitor and track general "functional" changes within plant communities, despite study sites being occupied by different species to disturbances such as changed grazing pressure (Dorrough et al. 2004, McIntyre 2008), eutrophication (Kuhner and Kleyer 2008, da Silveira Pontes et al. 2010), and identity and origin of neighbors (e.g., invasive exotic plants; Lavorel and Garnier 2002, McIntyre et al. 2005, McIntyre and Lavorel 2006). SLA and leaf nutrient content can be used as indicators of the relevant functioning of communities (Quetier et al. 2007). These leaf traits represent the investment plants make in the production of photosynthate, and uptake of mineral nutrients for metabolism for the construction of leaves, stems, roots, and reproductive organs (Wright et al. 2004). These same traits, SLA and leaf nutrient contents, may then be useful for measuring the induced response of different plant life forms to herbivory and test how alterations to leaf traits by herbivores then, in turn, explain community dynamics.

The few studies that have considered the consequences of herbivores on plant traits have tended to either research the impacts of large ungulates (Dorrough and Scroggie 2008) or insect herbivores (Peeter 2002) with the exception being Lind et al. (2012), whose study included both. Yet, herbivores of different body size, function, and behavior inhabit grassland systems; and therefore, could differently affect how plants invest in the construction of leaves, a plant's essential photosynthetic apparatus, and therefore, its key revenue stream (Wright et al. 2005).
In this study, we assessed how progressive exclusion of diverse aboveground herbivore communities affected the morphology and chemistry of the leaves grown by different plant life forms in two subalpine grassland types with different land-use history. More specifically, we excluded large, medium, and small mammals as well as invertebrates from two subalpine grassland types: (1) heavily grazed, rather nutrient rich, short-grass vegetation and (2) lightly grazed, lower nutrient, tall-grass vegetation (Schütz et al. 2006) and evaluated how these treatments affected plant traits in terms of both structure and function.

We focused on measuring "soft traits," SLA, and various leaf nutrient contents (i.e., nitrogen $[\mathrm{N}]$, carbon $[\mathrm{C}]$, phosphorus $[\mathrm{P}]$, potassium $[\mathrm{K}]$, sodium $[\mathrm{Na}]$, and calcium $[\mathrm{Ca}]$ ) across the progressive exclusion treatments, because numerous studies have found these traits will manifest differently within plants depending on abiotic and biotic conditions (Diaz et al. 2015). We then tested how these variations correlated with changes in dominance of the life form after five years. These correlations allowed us to tease apart whether leaf traits known to be indicative of investments and revenue streams for plants (Wright et al. 2004) were changed with the progressive removal of herbivores, and whether these changes presented a fitness advantage for some life forms over others depending on the relative productivity of the grassland. We expected to find decreased nutrients in the leaves and increased LA with the progressive exclusion of herbivores with the largest differences occurring between treatments where all herbivores have access to the plots vs. treatments where all are excluded. We expected to find this phenomenon of increased resource efficiency in the production of leaves with progressive exclusion of herbivores as leaves will age without the selective pressure of herbivores and some nutrients are mobile being shifted from older to younger plant tissue. We also expected to find a larger response in legumes and forbs vs. the grasses and sedges because of leaf shapes and plasticity; and a larger response in the more heavily grazed and nutrient rich short-grass vegetation because of higher availability of soil nutrients.

\section{Materials And Methods}

\section{Study area}

Our study was conducted in the Swiss National Park (SNP; $170 \mathrm{~km}^{2}$ in area) located in the southeastern part of Switzerland at elevations between 1,350 and 3,170 m above sea level (see also Risch et al. 2013). The SNP, founded in 1914, has received minimal human disturbance for the past $100 \mathrm{yr}$ (no hunting, fishing, or camping, visitors are not allowed to leave the trails). The park's subalpine grasslands are characterized by large ( $>1$ ha) homogeneous patches of short- and tall-grass vegetation that represent different historical management as well as grazing regimes by wild ungulates: short-grass vegetation 
developed in areas where cattle and sheep rested (high nutrient input) during agricultural land-use (from the 14th century until 1914); tall-grass vegetation developed in areas where cattle and sheep used to graze, but did not rest (Schütz et al. 2003, 2006). The former resting places became favorite grazing sites of red deer (Cervus elaphus L.) after the parks foundation and developed into shortgrass vegetation. This vegetation type is generally more productive than the tall-grass vegetation. Roughly $60 \%$ of the biomass is consumed in the short grass compared to $<20 \%$ in tall-grass vegetation (Schütz et al. 2006, Risch et al. 2013). The short-grass vegetation is dominated by grasses (Festuca rubra L., Briza media L.), while the tallgrass vegetation is dominated by sedges (Carex sempervirens Vill.). A diverse herbivory community coexists on these subalpine grasslands, which can be divided into four groups based on body size/mass: large (red deer and chamois [Rupricapra rupricapra L.]; 30-150 kg), medium (marmot [Marmota marmota L.] and mountain hare [Lepus timidus L.]; 3-6 kg), and small vertebrate herbivores (small rodents: e.g. Clethrionomys spp., Microtus spp., Apodemus spp.; 30-100 g), as well as invertebrates (e.g. grasshoppers, caterpillars, cicadas, $<5 \mathrm{~g}$ ).

\section{Experimental design}

We selected 18 subalpine locations (9 short-grass, 9 tall-grass vegetation) distributed over six subalpine grasslands throughout the park, located on dolomite parent material at altitudes of $1,975-2,300 \mathrm{~m}$. We established exclosure networks at each location in spring 2009 (early June), immediately after snowmelt (see also Appendix S1: Fig. S1). We selected three large (>10 ha) and three small ( $<3$ ha) grasslands. In the large grasslands, we established four exclosure networks (two in short- and two in tall-grass vegetation); in the small grasslands, one exclosure network was established in each of the two vegetation types. Each exclosure network consisted of a total of five plots $(2 \times 3 \mathrm{~m})$ that progressively excluded the different herbivores listed above (further labeled according to the herbivore guilds that had access to the respective plots $\mathrm{L} / \mathrm{M} / \mathrm{S} / \mathrm{I}, \mathrm{M} / \mathrm{S} / \mathrm{I}, \mathrm{S} / \mathrm{I}, \mathrm{I}$, and None; where $\mathrm{L}$ is large mammals, $\mathrm{M}$ is medium mammals, $\mathrm{S}$ is small mammals, I is invertebrates, and None means no herbivores had access; Appendix S1: Fig. S1). The L/M/S/I plot (not fenced) was located at least $5 \mathrm{~m}$ away from the $2.1 \mathrm{~m}$ tall and $7 \times 9 \mathrm{~m}$ main electrical fence that enclosed the other four exclosure types (for details, see Risch et al. 2013, Haynes et al. 2014). Within each main fence we randomly established four plots: (1) The M/S/I plots remained unfenced and provided access for all but ungulates. (2) The S/I plots were surrounded by a meshed $(10 \times 10 \mathrm{~cm})$ electrical fence that provided access for $\mathrm{S}$ and I. Note that the bottom $10 \mathrm{~cm}$ of this fence remained non-electrified to allow save access for S. (3) The I plots were surrounded by metal mesh $(2 \times 2 \mathrm{~cm})$ doubled at the bottom to exclude all mammals. (4) The None plots were surrounded by a $1 \mathrm{~m}$ tall mosquito net $(1.5 \times 2 \mathrm{~mm})$ to exclude all herbivores. The top of the plot was covered with a mosquito meshed wooden frame roof mounted to the corner posts (Risch et al. 2013, Haynes et al. 2014).

In addition, we established six "micro-climate control" exclosures to assess whether the design of the None exclosure (mesh and roof) affected the response variables within the plots and therefore might have influenced the results found (for more detail, see Risch et al. 2013). We were able to confirm that differences in plant (vegetation height, aboveground biomass, etc.) and soil properties (soil temperature, moisture, etc.) found between the I and the None treatments were not due to the construction of the None exclosure but a function of herbivore exclosure (Risch et al. 2013). The fences were dismantled every year in late October to protect them from snow pressure and avalanches and erected again in early May the following year immediately after snowmelt. In October 2013, the entire experiment was dismantled and all material removed from the SNP.

\section{Assessing plant functional traits of selected species}

In July 2013 (in the fifth season of exclusion), we randomly collected five fully developed leaves with no signs of herbivore damage from five mature individuals of eight plant species representing four life forms (Legume, Trifolium repens L., Lotus corniculatus L.; Forb, Galium anisophyllon Vill., Crepis alpestris [Jacq.] Tausch; Grass, F. rubra L., B. media L.; Sedge, C. sempervirens Vill., Carex caryophyllea Latour.). These species were the most dominant within each life form group across both vegetation types in terms of both frequency and cover. Measuring the same species as representative of our life form groups allowed us to test how differences in the productivity of grasslands can alter how herbivores induce plant traits. We collected leaves from these species (if present) in each of the $902 \times 3 \mathrm{~m}$ treatment plots with the standardized protocols detailed by Cornelissen et al. (2003).

Collected leaves for each species in each plot were combined, scanned for area using a flat bed scanner (Epson perfection V300, Tokyo, Japan) and image analysis software (ImageJ; Abramoff et al. 2004), dried, and weighed (dry mass). SLA was calculated as LA $\left(\mathrm{mm}^{2}\right) /$ dry mass (g). An additional 10 leaves per species were collected (where available), dried, combined with the leaves used for SLA measurement, ground, and analyzed for total leaf nutrients. Nitrogen $(\mathrm{N})$ and carbon $(\mathrm{C})$ were obtained by combustion using a LECO TruSpec analyzer (St. Joseph, Michigan, USA). Phosphorus (P), potassium $(\mathrm{K})$, calcium $(\mathrm{Ca})$, and sodium $(\mathrm{Na})$ were obtained using a Varian Vista Pro ICPOES instrument on samples that were open digested with a 5:1 nitric and perchloric acids (Rayment and Higginson 1992). We then analysed leaf nutrient levels by dividing nutrient concentration levels into the size of the leaves analysed, e.g., measure of level of nutrients depending on LA; $\mathrm{LA} / \mathrm{C}\left(\mathrm{mm}^{2} /\right.$ mass, where mass is measured as percentage of total dry mass), LA/N ( $\left.\mathrm{mm}^{2} / \mathrm{mass}\right), \mathrm{LA} / \mathrm{P}$ ( $\left.\mathrm{mm}^{2} / \mathrm{mass}\right), \mathrm{LA} / \mathrm{K}$ ( $\left.\mathrm{mm}^{2} / \mathrm{mass}\right), \mathrm{LA} /$ 
$\mathrm{Ca}\left(\mathrm{mm}^{2} / \mathrm{mass}\right)$, and $\mathrm{LA} / \mathrm{Na}\left(\mathrm{mm}^{2} / \mathrm{mass}\right)$. We used LA because of associations found between trait distributions and photosynthetic function, the relevance of LA to herbivory (Lind et al. 2012) and in consideration of the recently identified limitations of normalizing trait values by mass (Osnas et al. 2013). We also show mean values for foliar nutrient data (see Appendix S1: Fig. S3).

\section{Statistical analyses}

All statistical analyses were performed in $\mathrm{R}$ version 3.2.2 2015-08-14 (R Development Core Team 2013). We developed linear mixed models estimated with maximum likelihood using the lme4 library (Bates et al. 2012) to investigate how herbivore exclusion affected SLA and LA divided by leaf nutrients. Exclosure network was included as a random factor nested within grassland following our experimental design (Bolker et al. 2008). We then used diagnostic plots to check model assumptions of no correlations between observations within groups (Pinheiro and Bates 2000). We conducted these analyses for each vegetation type, short grass and tall grass, separately. The SLA and individual LA/nutrient measures were the dependent variables, modeled as a function of the fixed effects of treatment and life form (i.e., forb, grass, legume, and sedge). We then used the ANOVA function available in the LmerTest library that calculates denominator degrees of freedom for $F$ statistics including $P$ values using Satterthwaite's approximation. The ANOVA function in LmerTest summarizes $F$ statistics for the main effects, conducts likelihood ratio tests to test the significance of random effects, and compares differences between each factor level (Kuznetsova et al. 2016).

We then used generalized linear regression models to test correlations between dominance (i.e., LA/frequency) and changes in SLA and leaf nutrients depending on herbivore exclusion treatments. Therefore, dominance was the dependent variable and leaf traits and treatment the independent variables. Because, we tested the response of seven different traits in each group of analyses, it was necessary to address issues with the inflation of the alpha level, which increases the probability of a family-wise Type 1 error. To reduce the probability of a family-wise Type 1 error, we corrected $P$ values using a sequential Holm Sidàk, where $P$ values are ordered and the correction applied on each $P$ value,

$$
P_{\text {Sidák }}=1-(1-P)^{C-i+1}
$$

where $P$ is $P$ values from the statistical models, $c$ is the total number of hypotheses tested within a family, and $i$ is the stage in the sequential ordering until the first nonsignificant test in a family of $P$ values is found (Abdi 2010).

\section{Results \\ Herbivore-induced indirect effects on leaf traits depending on plant life form}

In the short-grass vegetation, SLA varied significantly depending on life form and treatment (Fig. 1a, Table 1; see Appendix S1: Fig. S2a and Table S1). No significant changes in SLA were found with grasses and sedges, but SLA of forbs and legumes were overall significantly higher in None plots compared to the L/M/S/I plots, where all herbivores were present. As expected, the SLA of forbs and legumes was generally higher than that of grasses and sedges. Similar treatment effects on SLA were detected in the tall-grass vegetation (Fig. 1h; see Appendix S1: Fig. $\mathrm{S} 2 \mathrm{~h}$ ), with forbs and legumes explaining the significant effect of treatment-dependent SLA increases and generally higher SLA than sedges and grasses (Fig. 1h; see Appendix S1: Fig. S1h, and Table S2a).

Generally, all LA/nutrient levels increased with the progressive exclusion of herbivores across all life forms in both vegetation types, showing that the resource use efficiency of the leaves increased as leaves increased in LA with a lower nutrient content (Fig. 1, Table 1, see Appendix S1: Fig. S2). Overall, the plants were more nutrient-rich in the short- compared to the tall-grass vegetation, because LA/nutrients was higher in the tall- compared to the short-grass vegetation for all life forms but forbs (see Appendix S1: Figs. S2 and S3).

More specifically, LA/C was higher in leaves when only invertebrates (I) or no herbivores (None) were present compared to the plots where all herbivores were present (L/M/S/I) in both vegetation types (Fig. 1b; see Appendix $\mathrm{S} 1$ : Tables S1, S2). In the short-grass vegetation, forb leaves had higher LA/C than all other life forms. Sedge leaves were higher in LA/C than legumes and grasses, and forb leaves were higher in LA/C than legumes in the tallgrass vegetation (Fig. 1b, i; see Appendix S1: Fig. S2b, i, Tables S1 and S2).

Leaf area/ $\mathrm{N}$ was significantly higher when all herbivores were excluded (None) compared to when all herbivores were present $(\mathrm{L} / \mathrm{M} / \mathrm{S} / \mathrm{I})$ in the short-grass vegetation and also the plants in plots where only invertebrates were present (I) had higher LA/N then when all animals had access (L/M/S/I; Fig. 1c; see Appendix S1: Fig. S2c, and Table S1). Legumes had significantly lower LA/N compared to all other life forms. In the tall-grass vegetation, the L/M/S/I plots had significantly lower LA/N than all

FIG. 1. Means and standard errors for specific leaf area (SLA) and LA/nutrients (LA/C, LA/N, LA/P, LA/Na, LA/Ca, LA/K; measured as $\mathrm{mm}^{2} /$ mass, where mass is measured as percentage of total dry mass). (a-g) Response of these leaf traits to progressive herbivore exclusions in the two vegetation types, (h-o) leaf traits of the different life forms in the two vegetation types. The herbivore treatments progressively excluded herbivores by body size. The codes provided on the $x$-axis indicate which group of herbivores had access to the plots: L/M/S/I, large mammals, medium mammals, small mammals and invertebrates had access; M/S/I, medium mammals, small mammals, and invertebrates had access; S/I, small mammals and invertebrates had access; I, invertebrates had access; None, no herbivores had access. 

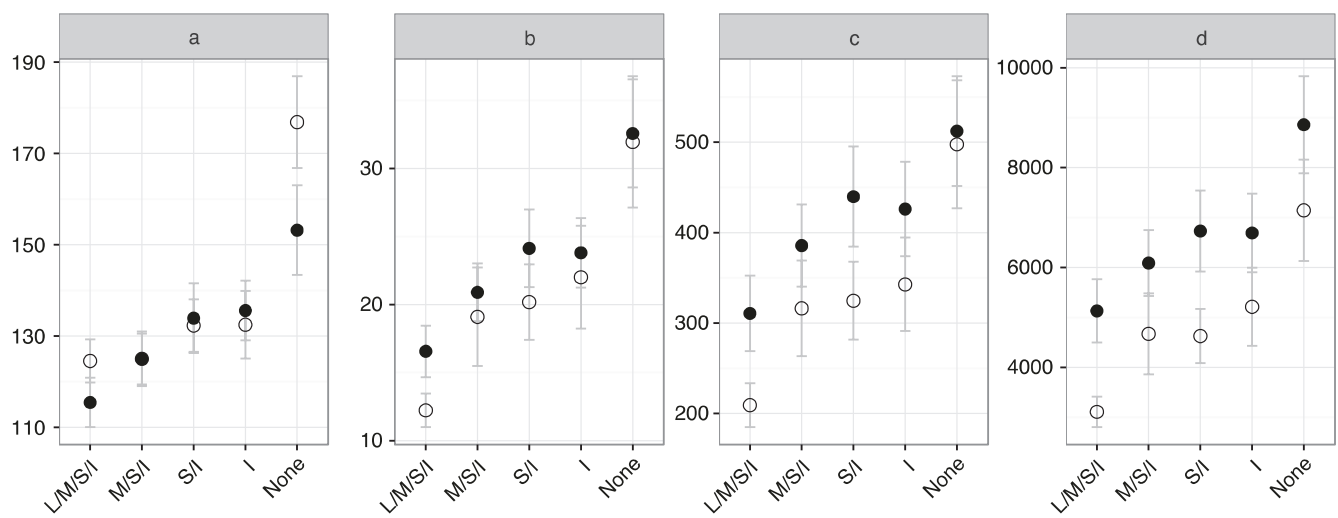

$\mathrm{SLA}-\left(\mathrm{mm}^{2} / \mathrm{g}\right)$

Leaf area $/ \mathrm{C}-\left(\mathrm{mm}^{2} / \mathrm{mass}\right)$

Leaf area $/ \mathrm{N}-\left(\mathrm{mm}^{2} / \mathrm{mass}\right)$

Leaf area/P - ( $\left.\mathrm{mm}^{2} / \mathrm{mass}\right)$
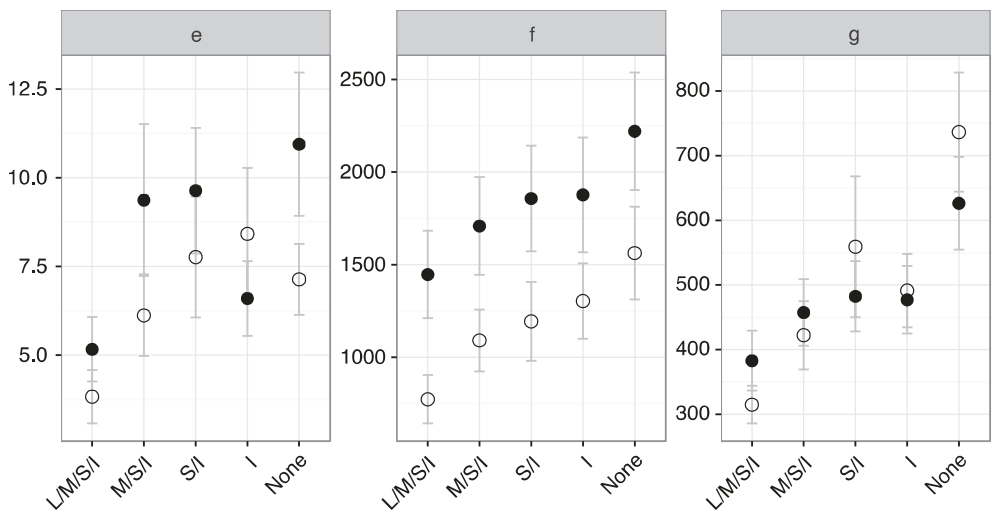

Vegetation

O Short grass

- Tall grass

Leaf area/ $\mathrm{Na}-\left(\mathrm{mm}^{2} / \mathrm{mass}\right)$

Leaf area/Ca - ( $\left.\mathrm{mm}^{2} / \mathrm{mass}\right)$

Leaf area $/ \mathrm{K}-\left(\mathrm{mm}^{2} / \mathrm{mass}\right)$

Treatment
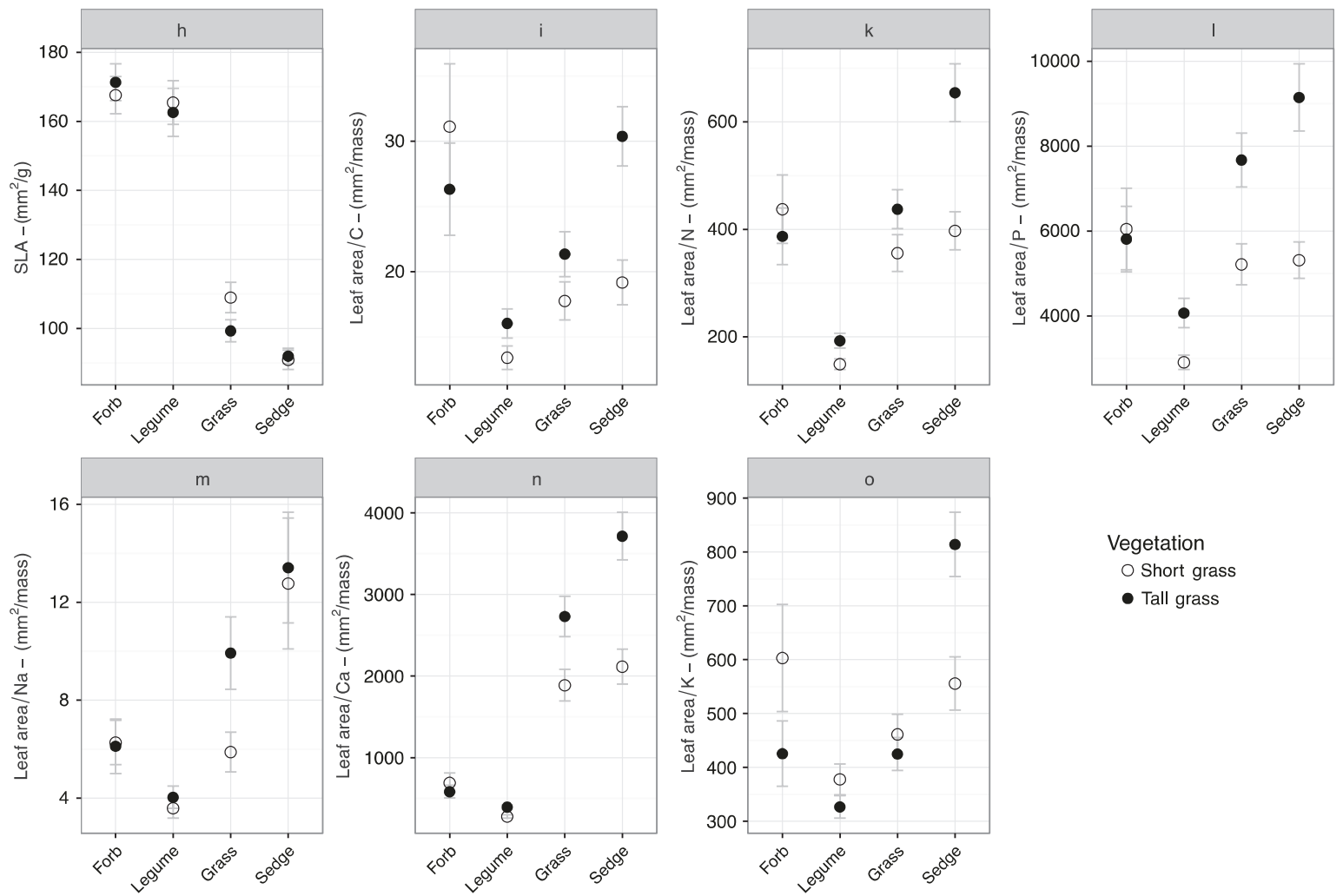

Vegetation

O Short grass

- Tall grass 
TABLE 1. Results from linear mixed-effect models conducted on specific leaf area (SLA) and leaf area (LA)/nutrients with a random effects structure of exclosure network nested in grassland.

\begin{tabular}{|c|c|c|c|c|}
\hline \multirow[b]{2}{*}{ Parameter } & \multicolumn{3}{|c|}{ Fixed effects } & \multirow{2}{*}{$\begin{array}{c}\text { Random effect } \\
\text { Grassland/exclosure }\end{array}$} \\
\hline & Treatment & Life form & Treatment:Life form & \\
\hline \multicolumn{5}{|c|}{ Short-grass vegetation } \\
\hline \multicolumn{5}{|c|}{ SLA } \\
\hline $\mathrm{df}$ & 4,264 & 3,265 & 12,263 & \\
\hline$F$ & 8 & 62 & 2 & \\
\hline$P$ & $<0.001(0.007)$ & $<0.001(0.007)$ & $0.01(0.07)$ & 0.009 \\
\hline \multicolumn{5}{|l|}{$\mathrm{LA} / \mathrm{C}$} \\
\hline df & 4 & 3 & 12 & \\
\hline$F$ & 5 & 7 & 0.4 & \\
\hline$P$ & $0.001(0.006)$ & $<0.001(0.006)$ & 0.98 & ns \\
\hline \multicolumn{5}{|l|}{$\mathrm{LA} / \mathrm{N}$} \\
\hline $\mathrm{df}$ & 4,264 & 3,265 & 12,263 & \\
\hline$F$ & 4 & 11 & 0.4 & \\
\hline$P$ & $0.003(0.009)$ & $<0.001(0.004)$ & 1 & 0.005 \\
\hline \multicolumn{5}{|l|}{$\mathrm{LA} / \mathrm{P}$} \\
\hline $\mathrm{df}$ & 4 & 3 & 12 & \\
\hline$F$ & 4 & 5 & 0.3 & \\
\hline$P$ & $0.002(0.008)$ & $0.002(0.004)$ & 1 & $\mathrm{~ns}$ \\
\hline \multicolumn{5}{|l|}{$\mathrm{LA} / \mathrm{Na}$} \\
\hline $\mathrm{df}$ & 4,264 & 3,265 & 12,263 & \\
\hline$F$ & 3 & 8 & 1 & \\
\hline$P$ & $0.03(0.03)$ & $<0.001(0.003)$ & 1 & 0.017 \\
\hline \multicolumn{5}{|l|}{$\mathrm{LA} / \mathrm{Ca}$} \\
\hline $\mathrm{df}$ & 4,227 & 3,228 & 12,227 & \\
\hline$F$ & 4 & 40 & 1 & \\
\hline$P$ & $0.001(0.005)$ & $<0.001(0.005)$ & 1 & $<0.001$ \\
\hline \multicolumn{5}{|l|}{$\mathrm{LA} / \mathrm{K}$} \\
\hline df & 4,276 & 3,277 & 12,275 & \\
\hline$F$ & 4 & 3 & 0.3 & \\
\hline$P$ & $0.003(0.006)$ & $0.02(0.02)$ & 0.99 & 0.040 \\
\hline \multicolumn{5}{|c|}{ Tall-grass vegetation } \\
\hline \multicolumn{5}{|l|}{ SLA } \\
\hline df & 4,258 & 3,259 & $12,257.8$ & \\
\hline$F$ & 7 & 81 & 1 & \\
\hline$P$ & $<0.001(0.007)$ & $<0.001(0.007)$ & 0.3 & 0.02 \\
\hline \multicolumn{5}{|l|}{$\mathrm{LA} / \mathrm{C}$} \\
\hline df & 4 & 3 & 12 & \\
\hline$F$ & 5 & 6 & 0.4 & \\
\hline$P$ & $<0.001(0.006)$ & $<0.001(0.006)$ & 1 & ns \\
\hline \multicolumn{5}{|l|}{$\mathrm{LA} / \mathrm{N}$} \\
\hline df & 2,252 & 3,253 & 12,252 & \\
\hline$F$ & 3 & 19 & 0.3 & \\
\hline$P$ & $0.03(0.06)$ & $<0.001(0.002)$ & 1 & 0.004 \\
\hline \multicolumn{5}{|l|}{$\mathrm{LA} / \mathrm{P}$} \\
\hline df & 4 & 13 & 12 & \\
\hline$F$ & 3 & 10 & 0.17 & \\
\hline$P$ & $0.01(0.05$ & $<0.001(0.005)$ & 1 & ns \\
\hline \multicolumn{5}{|l|}{$\mathrm{LA} / \mathrm{Na}$} \\
\hline $\mathrm{df}$ & 4,255 & 3,256 & 12,255 & \\
\hline$F$ & 3 & 8 & 1 & \\
\hline$P$ & $0.03(0.09)$ & $<0.001(0.003)$ & 0.3 & $<0.001$ \\
\hline \multicolumn{5}{|l|}{$\mathrm{LA} / \mathrm{Ca}$} \\
\hline df & 4,256 & 3,247 & 12,246 & \\
\hline$F$ & 2 & 72 & 0.2 & \\
\hline$P$ & 0.08 & $<0.001(0.001)$ & 1 & 0.001 \\
\hline
\end{tabular}


TABle 1. Continued.

\begin{tabular}{|c|c|c|c|c|}
\hline \multirow[b]{2}{*}{ Parameter } & \multicolumn{3}{|c|}{ Fixed effects } & \multirow{2}{*}{$\begin{array}{c}\text { Random effect } \\
\text { Grassland/exclosure }\end{array}$} \\
\hline & Treatment & Life form & Treatment:Life form & \\
\hline \multicolumn{5}{|l|}{$\mathrm{LA} / \mathrm{K}$} \\
\hline df & 4 & 3 & 12 & \\
\hline$F$ & 3 & 20 & 0.3 & \\
\hline$P$ & $0.02(0.08)$ & $<0.001(0.004)$ & 1 & ns \\
\hline
\end{tabular}

Notes: Fixed effects were treatment and life form. $F$ statistics, including $P$ values, were calculated using Satterthwaite's approximation. We corrected families of $P$ values using Holm's sequential Sidàk procedure; see Eq. 1 in Methods. The corrected $P$ values are shown in brackets. Significant results $(P<0.05)$ are shown in boldface type. In cells with "ns," random effects were not found to significantly explain variation, in these instances we used an ANOVA to analyze relationships.

but the M/S/I plots. These plots had lower LA/N compared to the plots where all animals were excluded (None; Fig. 1k; see Appendix S1: Fig. S2k and Table S2). Legumes had again the lowest LA/N followed by forbs and grasses with intermediate and sedges with the highest ratios within this vegetation type.

Leaf area/P differed when all animals were excluded (None) compared to when all animals were present (L/M/S/I) in both vegetation types (Fig. 1d, 1; see Appendix S1: Fig. S2d, 1, and Tables S1, S2). Legumes had significantly lower LA/P compared to all other life forms in the short-grass vegetation, while LA/P was higher in sedges compared to legumes and forbs in the tall-grass vegetation. LA/P also differed between grasses and legumes in this vegetation type.

Plant leaves in plots where all herbivores had access (L/M/S/I) had lower LA/Na compared to plots where large mammals were excluded (M/S/I). Sedges had higher $\mathrm{LA} / \mathrm{Na}$ compared to all other life forms in the short-grass vegetation (Fig. 1e; see Appendix S1: Fig. S2e and Table $\mathrm{S} 1)$. In the tall-grass vegetation $\mathrm{LA} / \mathrm{Na}$ was higher in all plots compared to $\mathrm{L} / \mathrm{M} / \mathrm{S} / \mathrm{I}$, with the exception of the I plots (Fig. 1e; see Appendix S1: Fig. S2e and Table S2). Grasses and sedges had higher LA/Na than legumes, and sedges also had higher LA/Na than forbs (Fig. 1m; see Appendix S1: Fig. S2 m and Table S2).

Leaves collected from plots that were open to all herbivores $(\mathrm{L} / \mathrm{M} / \mathrm{S} / \mathrm{I})$ were lower in $\mathrm{LA} / \mathrm{Ca}$ compared to plots were large mammals were excluded (M/S/I), which, however also had significantly lower LA/Ca compared to the plots where all herbivores were excluded (None) in the short-grass vegetation (Fig. 1f; see Appendix S1: Fig. S2f and Table S1). Grasses and sedges contained similar levels of LA/Ca content. Where in the tall-grass vegetation, forbs and legumes showed similar levels LA/Ca content, but no treatment effect was found (Fig. 1n; see Appendix S1: Fig. S2n, Tables S1 and S2).

In the short-grass vegetation, LA/K content was highest when all herbivores were excluded (None), and differed from all the other plots (Fig. 1g; see Appendix S1: Fig. S2g and Table S1). Legumes had lower LA/K compared to sedges and forbs. LA/K only differed between the L/M/S/I and None plots in the tall-grass vegetation and sedges had much higher $\mathrm{LA} / \mathrm{K}$ compared to the rest of the life forms (Fig. 1o; see Appendix S1: Fig. S2o and Table S2).

\section{Relationship between herbivore-induced trait responses and life form dominance}

In the short grass vegetation, we found a positive correlation between forb dominance and SLA (Table 2), but this change was unrelated to treatments, indicating variability across our exclosure network. However, as forb SLA increased across our treatments (see Appendix S1: Fig. S2a and Table S1), but dominance did not, herbivore exclusion caused forbs to produce fewer, but larger leaves measured as LA (Fig. 2a). At the same time an increase in LA/nutrients was observed (Table 2; see Appendix S1: Fig. S2b-g). Changes in legume dominance were significantly related to changes in LA/nutrients as we found positive relationships with all nutrients (Table 2; see Appendix S1: Fig. S2a and Table S1), suggesting that the production of leaves by legumes is increasing in resource use efficiency with the progressive exclusion of herbivores (Fig. 2b, Table 2; see Appendix S1: Fig. S2b-g). Contrastingly, grass SLA did not increase across our treatments (see Appendix S1: Fig. S2a and Table S1), but LA/nutrients did increase; therefore, the positive increase found between treatments and grass dominance suggests grasses are producing more tillers/leaves when fewer herbivores were present and that these leaves are more resource use efficient (Fig. 2c, Table 2; see Appendix S1: Fig. S2b-g). For sedges, we found no relationships between dominance, SLA, and any LA/nutrients (Table 2). The progressive exclusion of herbivores in the short-grass vegetation thus left sedges unaffected (Fig. 2d).

Similarly in the tall-grass vegetation, forbs responded to the progressive herbivore exclusions with fewer, but larger, more resource-efficient leaves (Fig. 2e, Table 3). Contrastingly, legume dominance did not show a significant relationship with variation in SLA or LA/nutrients (Table 3). However, as SLA increased across the treatments (see Appendix S1: Fig. S2h and Table S2), progressive herbivore exclusion led to legumes producing fewer, but larger, leaves while the efficiency remained unchanged (Fig. 2f, Table 3). Grass dominance was positively related to $\mathrm{LA} /$ nutrients (Table 3 ). As neither 
TABLE 2. Short-grass vegetation results conducted to assess the potential drivers of life form dominance in response to herbivory treatments and the changes in specific leaf area (SLA), leaf area $(\mathrm{LA}) / \mathrm{C}, \mathrm{LA} / \mathrm{N}, \mathrm{LA} / \mathrm{P}, \mathrm{LA} / \mathrm{Na}, \mathrm{LA} / \mathrm{Ca}$, and LA/K using generalized linear regression models.

\begin{tabular}{lllll}
\hline \hline Life form and trait & $F$ & $P$ & df & $R^{2}$ \\
\hline Forb & & & \\
\hline
\end{tabular}

Forb

SLA

Treatment

SLA:Treatment

$\begin{array}{ccc}0.5 & 0.7 & 4,73\end{array}$

Legume

SLA

Treatment

SLA:Treatment

Grass

SLA

Treatment

SLA:Treatment

Sedge

SLA

Treatment

SLA:Treatment

Forb

LA/C

Treatment

LA/C:Treatment

Legume

$\mathrm{LA} / \mathrm{C}$

Treatment

LA/C:Treatment

Grass

$\mathrm{LA} / \mathrm{C}$

Treatment

LA/C:Treatment

Sedge

LA/C

Treatment

LA/C:Treatment

Forb

LA/N

Treatment

LA/N:Treatment

Legume

$\mathbf{L} / \mathbf{N}$

Treatment

LA/N:Treatment

Grass

LA/N

Treatment

LA/N:Treatment

Sedge

LA/N

Treatment

LA/N:Treatment

Forb

$\mathbf{L A} / \mathbf{P}$

Treatment

LA/P:Treatment

0.15

0.14

0.44

0.37

0.52

0.16

0.45

0.39

0.57

$<0.001(0.005) \quad 1,74$

$<0.001(0.006) \quad 4,74$

0.08

4,74

$0.2 \quad 1,38$

$1.04,38$

1.0

4,38

0.15

0.48

$<0.001(0.007) \quad 1,73$

4,73

$0.08 \quad 4,73$

$\begin{array}{lll}2 & 0.08 & 4,73\end{array}$

TABle 2. Continued.

\begin{tabular}{lcccc}
\hline \hline Life form and trait & $F$ & $P$ & df & $R^{2}$ \\
\hline Legume & & & & 0.31 \\
$\quad$ LA/P & $\mathbf{7}$ & $\mathbf{0 . 0 0 9}(\mathbf{0 . 0 4})$ & 1,65 & \\
Treatment & $\mathbf{5}$ & $\mathbf{0 . 0 0 1}(\mathbf{0 . 0 0 7})$ & 4,65 & \\
LA/P:Treatment & 0.4 & 1.0 & 4,65 & \\
Grass & & & & 0.49 \\
LA/P & $\mathbf{4 5}$ & $\mathbf{< . 0 0 1}(\mathbf{0 . 0 0 6 )}$ & 1,74 & \\
Treatment & $\mathbf{5}$ & $\mathbf{0 . 0 0 1}(\mathbf{0 . 0 0 6 )}$ & 4,74 & \\
LA/P:Treatment & 2 & 0.10 & 4,74 & \\
Sedge & & & & 0.12 \\
LA/P & 1 & 0.30 & 1,38 & \\
Treatment & 0.7 & 1.0 & 4,38 & \\
LA/P:Treatment & 0.3 & 0.0 & 4,38 & \\
$\quad$ & & & & 0.22
\end{tabular}

Forb

LA/Na

Treatment

LA/Na:Treatment

Legume

$\mathrm{LA} / \mathrm{Na}$

Treatment

LA/Na:Treatment 0.7

Grass

LA/Na

Treatment

LA/Na:Treatment 0.5

Sedge

$\mathrm{LA} / \mathrm{Na}$

Treatment

LA/Na:Treatment

Forb

LA/Ca

Treatment

LA/Ca:Treatment

Legume

LA/Ca

Treatment

LA/Ca:Treatment

Grass

LA/Ca

Treatment

LA/

$\mathrm{Ca}$ :Treatment

Sedge

$\mathrm{LA} / \mathrm{Ca}$

Treatment

LA/

Ca:Treatment

Forb

LA/K

Treatment

LA/K:Treatment

Legume

LA/K
Treatment

Grass

LA/K
LA/K:Treatment
$<0.001(0.007) \quad 1,73$

$\begin{array}{cc}0.2 & 1,65 \\ \mathbf{0 . 0 0 2 ( 0 . 0 1 )} & 4,65 \\ 1.0 & 4,65\end{array}$

$<\mathbf{0 . 0 0 1 ( 0 . 0 0 6 ) \quad 1 , 7 4}$

0.007 (0.04) $\quad 4,74$

$1.0 \quad 4,74$

0.27

$0.5 \quad 1,38$

$0.5 \quad 4,38$

$0.06 \quad 4,38$

0.41

$<0.001(0.007) \quad 1,73$

$1.0 \quad 4,73$

$0.1 \quad 4,73$

0.32

$0.006(0.03) \quad 1,65$

0.001 (0.007) 4,65

$1.0 \quad 4,65$

0.52

$<0.001(0.006) \quad 1,74$

$<0.001$ (0.006) 4,74

$\begin{array}{lll}0.8 & 0.5 & 4,74\end{array}$

0.16

$0.2 \quad 1,38$

$\begin{array}{lll}0.8 & 1.0 & 4,38 \\ 0.5 & 1.0 & 4,38\end{array}$

$\begin{array}{lll}0.8 & 1.0 & 4,38 \\ 0.5 & 1.0 & 4,38\end{array}$

0.34

0.21

$9 \quad 0.004(0.02) \quad 1,73$

$\begin{array}{lll}0.5 & 1.0 & 4,73\end{array}$

$\begin{array}{lll}2 & 0.08 & 4,73\end{array}$

0.26

$0.2 \quad 1,65$

$0.002(0.001) \quad 4,65$

$1.0 \quad 4,65$

0.34
$17 \quad<0.001(0.007) \quad 1,74$ 
TABle 2. Continued.

\begin{tabular}{lcccc}
\hline \hline Life form and trait & $F$ & $P$ & $\mathrm{df}$ & $R^{2}$ \\
\hline Treatment & $\mathbf{4}$ & $\mathbf{0 . 0 0 8}(\mathbf{0 . 0 0 4})$ & 4,74 & \\
LA/K:Treatment & 2 & 0.2 & 4,74 & \\
Sedge & & & & 0.15 \\
LA/K & 2 & 0.1 & 1,38 & \\
Treatment & 0.8 & 1.0 & 4,38 & \\
LA/K:Treatment & 0.4 & 1.0 & 4,38 & \\
\hline
\end{tabular}

Notes: Significant results are shown in boldface type. We corrected families of $P$ values using Holm's sequential Sidàk procedure; see Eq. 1 in Methods. The corrected $P$ values are shown in brackets.

dominance nor SLA was altered by our treatments (Fig. 1h, Table 3), progressive herbivore exclusion only increased the resource use efficiency of the grasses (Fig. 2g). The same was true for sedges (Fig. 2h, Table 3; see Appendix S1: Fig. S2h and Table S2). In addition, we detected a negative relationship between sedge dominance and SLA, which indicated variation in responses between fences (Table 3). As would be expected, where sedge dominance was high, SLA tended to be lower.

\section{Discussion}

Herbivores damage plants and this damage is generally non-lethal, ubiquitous, and unevenly inflicted on life forms and plant species (Utsumi et al. 2010a, $b$ ). Types of herbivory damage are numerous, ranging from complete tissue removal to subtle physiological and morphological changes in traits. It is the implications of these subtle changes to physiology and morphology of plants that have largely been ignored in community ecology (but please see Lind et al. 2012). Here, we find that soft and relatively easy-tomeasure leaf traits (SLA, LA/nutrients) can change in a predictable manner (e.g., leaf economic spectrum; Lavorel and Garnier 2002, Wright et al. 2004, McIntyre 2008, Meer et al. 2009), and that these changes in some instances correlate with changes in life form dominance.

We measured the same eight species representing four life forms (i.e., grasses, forbs, legumes, and sedges), across two grassland types with different land-use histories that are characterized by high productivity and high biomass consumption (short-grass vegetation) vs. low productivity and low biomass consumption (tall-grass vegetation). Regardless of grassland type and life form, we found there is not just one generalizable plant response to the progressive release from herbivory but instead we found six generalizable ways that plants can respond: (1) increased leaf size and resource use efficiency, but a reduction in the number of leaves, (2) increased leaf size and resource use efficiency where lower nutrient levels are invested in leaf construction, (3) increased leaf size but a reduction in the number of leaves, (4) increased number of leaves produced and increased resource use efficiency, (5) increased resource use efficiency of leaves only, and (6) no response in terms of leaf construction or dominance.

\section{Changes in life form dominance}

Historically, a change from a predominance of taller grasses to low-lying forbs and a doubling in plant species richness in the short-grass vegetation took place in the SNP (Schütz et al. 2000, 2003). These changes were brought about because of red deer grazing heavily on these grasslands after their population experienced exponential growth between 1940 and 1970 (Haller 2002). The increase in cover of forbs and legumes such as G. anisophyllon and T. repens (included in this study) resulted from their ability to avoid grazing because of their short prostrate structure, a structural trait found by global analyses to characterize plant communities following grazing impacts (Diaz et al. 2007). In our study, forbs and legumes were found to alter leaf construction in response to a release from herbivory, which was measured as an increase in SLA, where LA increased and the amount of dried tissue contained within the leaf was proportionally lower (Wilson et al. 1999, Firn et al. 2012). However, changes in SLA did not correlate to an increase in dominance for forbs, as the strategy employed by forbs was to reduce leaf production. Legume dominance, in contrast, increased across our treatments. Grazers have a high affinity for legumes; thus, the positive response when grazing pressure is relieved is in line with the results of previous studies (Vitousek et al. 2002, 2010). However, due to their low shade tolerance and small structure overtime, it is likely that legume dominance may be superseded by grasses, generally considered a more competitive life form, in the highly productive short-grass vegetation (Vitousek et al. 2002, 2010).

Unlike forbs and legumes, sedge and grass dominance was not correlated with changes in SLA values. Sedges showed no significant change in dominance with the progressive exclusion of herbivores as well as few changes in leaf traits. Grasses increased in dominance by increasing tiller density, which may provide a competitive advantage (see also Sbrissa et al. 2001). The production of additional leaves/tillers demands the acquisition of nutrients from other sources than the leaves themselves. This could happen by decreasing the investment in root growth when grazing pressure is lowered (Milchunas and Lauenroth 1989) or by benefiting from the nutrient pools contained within the soil of nutrient-rich environments (Tilman 1988, Goldberg and Landa 1991). We do not have information on root production of grasses, but we do know that overall root biomass did not differ among our treatments (Risch et al. 2015). However, since the soil sustaining the short-grass vegetation is fairly nutrient rich for the constrained area of the SNP (Schütz et al. 2006), and Risch et al. (2015) showed increased soil $\mathrm{N}$ mineralization rates with progressive herbivore exclusion, our findings suggest that the mechanism behind the increased grass dominance was likely associated with increased soil nutrient exploitation.

Although we did not measure anti-herbivore compounds (defense compounds) in leaves, response of our 

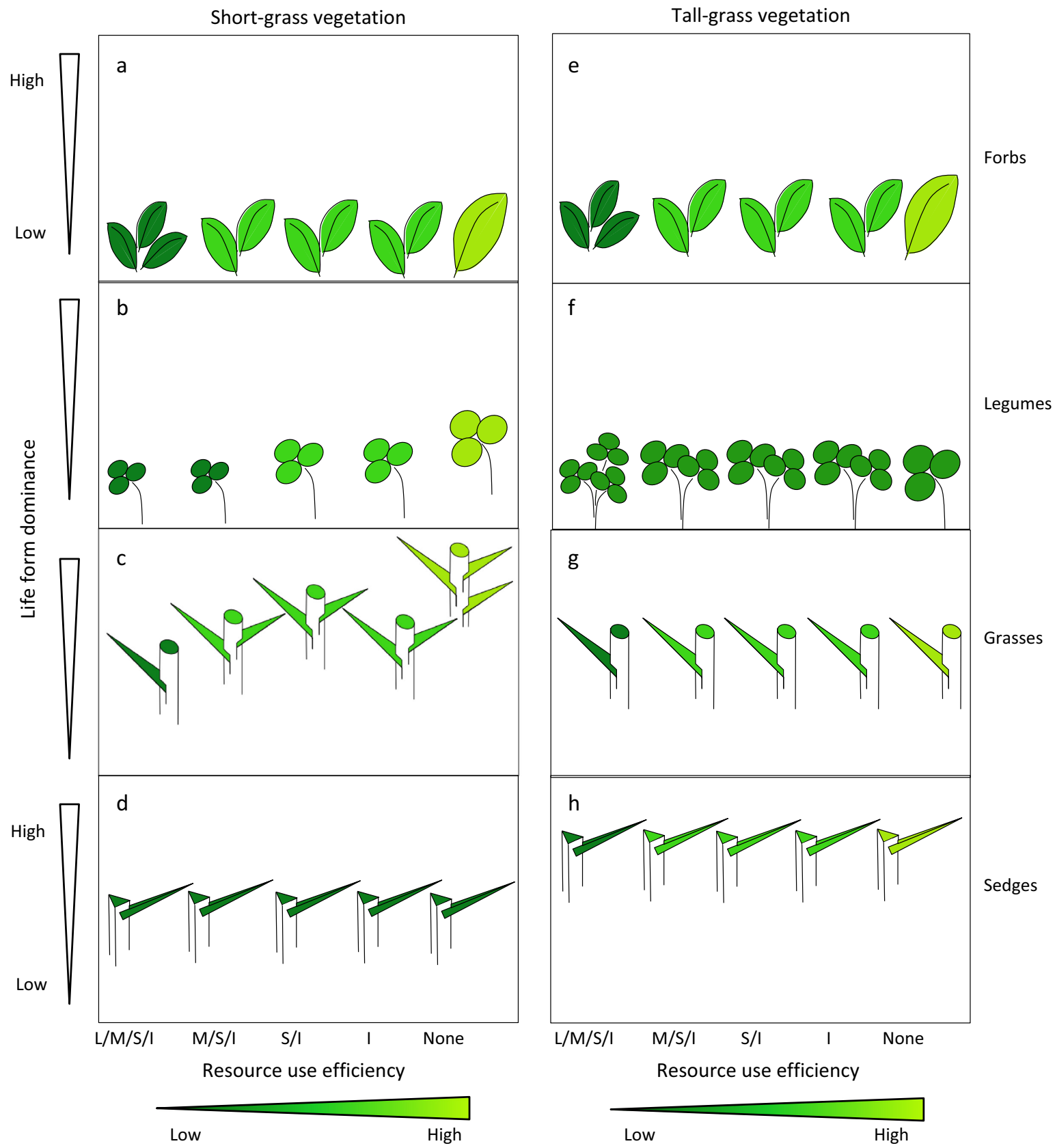

FIG. 2. Summarized responses (statistics in Tables 2, 3, Appendix S1: Table S1) of how progressive herbivore exclusion ( $x$-axis) alters life form dominance ( $y$-axis), resource use efficiency (dark green leaves show low resource use efficiency, light green leaves show high efficiency), leaf size, and number of leaves. (a-d) Life form responses in the short-grass vegetation, (e-h) life form responses in the tall-grass vegetation. The codes shown on the $x$-axis indicate which group of herbivores had access to the plots: L/M/S/I, large mammals, medium mammals, small mammals, and invertebrates had access; M/S/I, medium mammals, small mammals, and invertebrates had access; S/I, small mammals and invertebrates had access; I, invertebrates had access; None, no herbivores had access.

grasses to progressively excluding herbivores supports the growth-defense hypothesis (sensu Coley et al. 1985). In resource-rich environments, fast-growing plants that invest relatively less in defense compounds suffer high herbivore damage. However, once released from grazing pressure, they can outcompete the other species due to faster growth rates (Lind et al. 2013). Consequently, if we were to continue our exclusion experiment, we would expect the vegetation to revert to the composition found in the area prior to the parks foundation (strong dominant tall-growing grasses) and that light limitation (Hautier et al. 2009) would become an important long-term driver of compositional change with a loss in plant species richness (Viola et al. 2010). 
TABLE 3. Tall-grass vegetation results conducted to assess the potential drivers of life form dominance in response to herbivory treatments and the changes in specific leaf area (SLA), leaf area $(\mathrm{LA}) / \mathrm{C}, \mathrm{LA} / \mathrm{N}, \mathrm{LA} / \mathrm{P}, \mathrm{LA} / \mathrm{Na}$, and LA/K using generalized linear regression models.

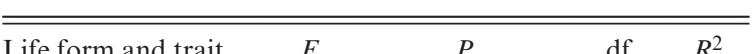

\begin{tabular}{ll}
\hline Life form and trait & $F$ \\
\hline Forb & \\
SLA & 1.0 \\
Treatment & 1.0 \\
SLA:Treatment & 0.7 \\
Legume & \\
SLA & 0.3 \\
Treatment & 2.0 \\
SLA:Treatment & 0.6 \\
Grass & \\
SLA & 7.0 \\
Treatment & 1.0 \\
SLA:Treatment & 2.0 \\
Sedge & \\
SLA & $\mathbf{1 2}$ \\
Treatment & 1.0 \\
SLA:Treatment & 0.8 \\
Forb & \\
LA/C & \\
Treatment & 2.0 \\
LA/C:Treatment & 2.0 \\
Legume & \\
LA/C & \\
Treatment & 2.0 \\
LA/C:Treatment & 0.3 \\
Grass & \\
LA/C &
\end{tabular}

LA/C

Treatment

LA/C:Treatment 4.0

Sedge

LA/C

Treatment

LA/C:Treatment 1.0

Forb

$\begin{array}{ll}\text { LA/N } & \mathbf{5 4} \\ \text { Treatment } & 2.0 \\ \text { LA/N:Treatment } & 3.0 \\ \text { Legume } & \end{array}$

LA/N $\quad 0.09$

Treatment 2.0

LA/N:Treatment 0.5

Grass

LA/N

Treatment

LA/N:Treatment

Sedge

$\begin{array}{ll}\text { LA/N } & \mathbf{3 8} \\ \text { Treatment } & 1.0 \\ \text { LA/N:Treatment } & 2.0\end{array}$

Forb

LA/P

Treatment -2.0

LA/P:Treatment 2.9

$0.4 \quad 4,74$

$0.1 \quad 4,74$

0.29

$<0.001$ (0.007) $\quad 1,47$

$0.5 \quad 4,47$

$<0.001(\mathbf{0 . 0 0 7 )} \quad 1,67$

$0.08 \quad 4,67$

$0.09 \quad 4,67$

$1.0 \quad 1,55$

$0.10 \quad 4,55$

$1.0 \quad 4,55$

$<0.001$ (0.006) $\quad 1,74$

$0.3 \quad 4,74$

$0.007 \quad 4,74$

$<0.001$ (0.005) $\quad 1,47$

$0.3 \quad 4,47$

$0.4 \quad 4,47$

$<0.001(0.007) \quad 1,67$

$0.09 \quad 4,67$

$0.04(0.20) \quad 4,67$

$1.0 \quad 1,55$

$0.09 \quad 4,55$

$1.0 \quad 4,55$

$<0.001$ (0.006) 1,74

$0.30 \quad 4,74$

$0.09 \quad 4,74$

$<0.001$ (0.005) 1,47

$0.3 \quad 4,47$

$0.2 \quad 4,47$

0.16

0.51

0.54

$<0.001(\mathbf{0 . 0 0 7}) \quad 1,67$

$0.08 \quad 4,67$

$0.03(0.2) \quad 4,67$
TABle 3. Continued.

\begin{tabular}{lcccc}
\hline \hline Life form and trait & $F$ & $P$ & df & $R^{2}$ \\
\hline Legume & & & & 0.18 \\
$\quad$ LA/P & 0.5 & 0.5 & 1,55 & \\
Treatment & 2.0 & 0.09 & 4,55 & \\
LA/P:Treatment & 0.7 & 1.0 & 4,55 & \\
Grass & & & & 0.21 \\
LA/P & $\mathbf{1 2}$ & $<\mathbf{0 . 0 0 1}(\mathbf{0 . 0 0 6})$ & 1,74 & \\
Treatment & 1.0 & 0.4 & 4,74 & \\
LA/P:Treatment & 1.0 & 04 & 4,74 & \\
Sedge & & & & 0.55 \\
$\quad$ LA/P & $\mathbf{5 0}$ & $<\mathbf{0 . 0 0 1}(\mathbf{0 . 0 0 5})$ & 1,47 & \\
Treatment & 1.4 & 0.2 & 4,47 & \\
$\quad$ LA/P:Treatment & 0.9 & 0.5 & 4,47 & \\
Forb & & & & 0.29
\end{tabular}

\section{LA/Na}

Treatment

LA/Na:Treatment

17

$0.5 \quad 4,47$

0.52 Grass

\section{LA/Ca}

Treatment

LA/Ca:Treatment

Sedge

\section{LA/Ca}

Treatment

LA/Ca:Treatment

Forb

\section{LA/K}

Treatment

LA/K:Treatment

Legume

$\mathrm{LA} / \mathrm{K}$

Treatment

LA/K:Treatment

Grass

LA/K

Treatment

LA/K:Treatment

$<0.001(0.007) \quad 1,67$

$0.2 \quad 4,67$

$0.4 \quad 4,67$

0.16

$1.0 \quad 1,55$

$0.1 \quad 4,55$

$1.0 \quad 4,55$

0.21

$0.1 \quad 1,74$

$0.4 \quad 4,74$

$0.02(0.1) \quad 4,74$

$0.2 \quad 1,47$

$1.0 \quad 4,47$

$0.3 \quad 4,47$

0.58

$<\mathbf{0 . 0 0 1 ( 0 . 0 0 7 )} \quad 1,67$

$0.05(0.20) \quad 4,67$

$0.20 \quad 4,67$

$0.50 \quad 1,55$

$0.10 \quad 4,55$

$0.90 \quad 4,55$

$<0.001(0.007) \quad 1,74$

$0.30 \quad 4,74$

$0.06 \quad 4,74$

$<0.001(\mathbf{0 . 0 0 5}) \quad 1,47$

$0.30 \quad 4,47$

$0.6 \quad 4,47$

0.58

$<0.001(0.007) \quad 1,67$

$0.06 \quad 4,67$

$0.1 \quad 4,67$

$1.0 \quad 1,55$

$0.08 \quad 4,55$

$0.5 \quad 4,55$

0.33 
Table 3. Continued.

\begin{tabular}{lcccc}
\hline \hline Life form and trait & $F$ & $P$ & df & $R^{2}$ \\
\hline Sedge & $\mathbf{5 2}$ & $\mathbf{< 0 . 0 0 1}(\mathbf{0 . 0 0 5 )}$ & 1,47 & \\
LA/K & 2.0 & 0.2 & 4,47 & \\
Treatment & 1.0 & 0.3 & 4,47 & \\
LA/K: Treatment & & & \\
\hline
\end{tabular}

Notes: Significant results are shown in boldface type. We corrected families of $P$ values using Holm's sequential Sidàk procedure; see Eq. 1 in Methods. The corrected $P$ values are shown in brackets.

In the tall-grass vegetation, forbs and legumes were also able to increase SLA when all herbivores were excluded (None), but this increase came at the cost of producing fewer leaves and therefore did not correlate with a change in dominance. Grasses and sedges showed no response in SLA, but also did not increase the number of leaves or tillers. As, again, Risch et al. (2015) showed no differences in root biomass among our treatments in the tall-grass vegetation, this suggests that soil nutrients are not as readily available for plant uptake in this vegetation type (tall grass). Indeed, historical plant surveys did not show any change in life form dominance in this vegetation over 100 years (Schütz et al. 2003), thus, our short-term results are not surprising. Together with the historical data they confirm the "inertia" low productive systems display when impacted by environmental change (Bardgett and Wardle 2003) and our results suggest that this inertia begins at the individual plant level.

\section{Changes in life form resource use efficiency}

The progressive exclusion of herbivores also positively affected the resource use efficiency (Wright et al. 2004, Westoby et al. 2006) of the different life forms for all but sedges in the short- and legumes in the tall-grass vegetation (displayed as change in the shade of green in Fig. 2). There are two possible explanations for these increases: progressive herbivore exclusion (1) reduced the palatability of the plants or (2) increased plant biomass (standing crop) and shading and therefore led to changes in photosynthetic activities of the plants. There is support for both pathways in the literature.

1. Positive grazer-grassland interactions, with higher forage quality when large herbivores (ungulates) were present, have been reported for grassland ecosystems around the globe (Frank et al. 1998). However, in our study, we were able to show that also smaller herbivores, in particular, the presence/ absence of invertebrates was important in shaping plant resource efficiencies and therefore potential differences in palatability of the plants. Literature on how the exclusion of invertebrates alters plant quality in ecosystems is rare (Loranger et al. 2012). However, for example, Belovsky and Slade (2000) showed that grasshopper grazing increased the litter quality $(\mathrm{N})$ of several (individual) grass species, which indicates that, as with large herbivores, invertebrates could cause positive grazer-grassland feedbacks.

2. Entire plants or individual leaves are known to increase their resource efficiency under shaded conditions. This lowers the photosynthetic rate per LA by up to $50 \%$ when measured near light saturation, but maximizes assimilation under low light conditions (Evans and Poorter 2001). When shaded, plants lower their maximal possible photosynthesis rates, but develop plant tissue that is able to perform better under the shaded conditions. These plants/leaves are better adapted to photosynthesis under lower light conditions compare to plants/leave growing in full sunlight.

\section{CONCLUSIONS}

Our results show that there may be no generalizable response of plants to herbivory. Traits that are altered by herbivore activity seem, for example, to depend on the life form/plant species studied, inter- vs. intra-life form/ plant species comparisons, type of herbivores considered (e.g., cattle, wild ungulates, invertebrates; Peeter 2002, Dorrough and Scroggie 2008, Lind et al. 2012), controlled environment experiments (greenhouse, garden, low number of species) vs. field experiments in communities rich in both plant and herbivore species (Denno and Kaplan 2007, McIntyre 2008, Firn et al. 2012), or environmental conditions at the study site (tropical, temperate, polar, humid, dry, productive, unproductive; Diaz et al. 2007).

What our results do show are that herbivore-induced indirect impacts matter to populations and communities because they sculpt leaf structure and influence subsequent functions and community composition. Vertebrate and invertebrate herbivore management should aim to maintain grazing pressure to benefit efficient investments in the construction of photosynthetic tissue. In more productive grasslands, management is, in addition, important for maintaining biodiversity because there is a propensity for a dominant life-form to be favored when herbivory pressure is reduced, as could happen through changes in herbivore communities (e.g., extinction, invasion), while lower productivity grasslands are more resilient to changing pressure from herbivores.

\section{ACKNOWLEDGMENTS}

We would like to thank various employees and volunteers of the Swiss Federal Institute for Forest, Snow, and Landscape Research and the Swiss National Park for assistance with fence construction and maintenance. We thank Constant Signarbieux and Felix Hernàndez for their invaluable help in the field and Emma LaDouceur and Max Rosenthal for sample processing in the laboratory. This study was funded by the Swiss National Science Foundation, SNF grant-no 31003A_122009/1 and SNF grant-no 31003A_140939/1. 


\section{Literature Cited}

Abdi, H. 2010. Holm's sequential Bonferroni procedure. Pages 573-577 in N. Salkind, editor. Encyclopedia of research design. Sage, Thousand Oaks, California, USA.

Abramoff, M. D., P. J. Magalhaes, and S. J. Ram. 2004. Image processing with ImageJ. Biophotonics International 11:36-42.

Bardgett, R., and D. A. Wardle. 2003. Herbivore-mediated linkages between aboveground and belowground communities. Ecology 84:2258-2268.

Bates, D., M. Maechler, and B. Bolker. 2012. Lme4. https:// cran.r-project.org/web/packages/lme4/lme4.pdf

Belovsky, G. E., and J. B. Slade. 2000. Insect herbivory accelerates nutrient cycling and increases plant production. Proceedings of the National Academy of Sciences USA 97:14412-14417.

Bolker, B. M., M. E. Brooks, C. J. Clark, S. W. Geange, J. R. Poulsen, M. H. H. Stevens, and J.-S. S. White. 2008. Generalized linear mixed models: a practical guide for ecology and evolution. Trends in Ecology \& Evolution 24: 127-135.

Coley, P. D., J. P. Bryant, and F. S. Chapin. 1985. Resource availability and plant antiherbivore defense. Science 230: 895-899.

Cornelissen, J. H. C., et al. 2003. A handbook of protocols for standardised and easy measurement of plant functional traits worldwide. Australian Journal of Botany 51:335-380.

da Silveira Pontes, L., F. Louault, P. Carrere, V. Maire, D. Andueza, and J. F. Soussana. 2010. The role of plant traits and their plasticity in the response of pasture grasses to nutrients and cutting frequency. Annals of Botany 105:957-965.

Delting, J. K. 1998. Mammalian herbivores: ecosystem-level effects in two grassland national parks. Wildlife Society Bulletin 26:423-435.

Denno, R. F., and I. Kaplan. 2007. Plant-mediated interactions in herbivorous insects: mechanisms, symmetry, and challenging the paradigms of competition past. Pages 19-49 in T. Ohgushi, T. P. Craig, and P. W. Price, editors. Ecological communities: plant mediation in indirect interaction webs. Cambridge University Press, Cambridge, UK.

Diaz, S., et al. 2004. The plant traits that drive ecosystems: evidence from three continents. Journal of Vegetation Science 15:295-304.

Diaz, S., et al. 2007. Plant trait responses to grazing - a global synthesis. Global Change Biology 13:313-341.

Diaz, S., et al. 2015. The global spectrum of plant form and function. Nature 529:167-171.

Dorrough, J., J. Ash, and S. McIntyre. 2004. Plant responses to livestock grazing frequency in an Australian temperate grassland. Ecography 27:798-810.

Dorrough, J., and M. Scroggie. 2008. Plant responses to agricultural intensification. Journal of Applied Ecology 45: 1274-1283.

Evans, J. R., and H. Poorter. 2001. Photosynthetic acclimation of plants to growth irradiance: the relative importance of specific leaf area and nitrogen partitioning in maximizing carbon gain. Plant, Cell and Environment 24:755-767.

Firn, J., S. M. Prober, and Y. M. Buckley. 2012. Plastic traits of an exotic grass contribute to its abundance but are not always favourable. PLoS ONE 7:e35870.

Frank, D. A., S. J. McNaughton, and B. Tracy. 1998. The ecology of the earth's grazing ecosystems. BioScience 48: 513-521.

Goldberg, D., and K. Landa. 1991. Competitive effect and response: hierarchies and correlated traits in the early stages of competition. Journal of Ecology 79:1013-1030.
Haller, H. 2002. Der Rothirsch im Schweizerischen Nationalpark und seiner Umgebung. Eine alpine Population von Cervus elaphus zeitlich und raeumlich dokumentiert. Nat.parkForsch 91.

Hautier, Y., P. A. Niklaus, and A. Hector. 2009. Competition for light causes plant biodiversity loss after eutrophication. Science 324:636-638.

Haynes, A.G., M. Schütz, N. Buchmann, D. S. Page-Dumroese, M. D. Busse, and A. C. Risch. 2014. Linkages between grazing history and herbivore exclusion on decomposition rates in mineral soils of subalpine grasslands. Plant and Soil 374:579 591. DOI: $10.1007 / \mathrm{s} 11104-013-1905-8$

Kuhner, A., and M. Kleyer. 2008. A parsimonious combination of functional traits predicting plant response to disturbance and soil fertility. Journal of Vegetation Science 19: 681-U642.

Kuznetsova, A., P. B. Brockhoff, and R. H. B. Christensen. 2016. lmerTest. https://cran.r-project.org/web/packages/ lmerTest/lmerTest.pdf

Lavorel, S., and E. Garnier. 2002. Predicting changes in community composition and ecosystem functioning from plant traits: revisiting the Holy Grail. Functional Ecology 16: $545-556$

Lind, E. M., E. P. Myron, J. Giaccai, and J. D. Parker. 2012. White-tailed deer alters specialist and generalist insect herbivory through plant traits. Environmental Entomology 41:1409-1416.

Lind, E. M., et al. 2013. Life history constraints in grassland plant species: A growth defense tradeoff is the norm. Ecology Letters 16:513-521.

Loranger, J., S. T. Meyer, B. Shipley, J. Kattge, H. Loranger, C. Roscher, and W. W. Weisser. 2012. Predicting invertebrate herbivory from plant traits: evidence from 51 grassland species in experimental monocultures. Ecology 93: 2674-2682.

McIntyre, S. 2008. The role of plant leaf attributes in linking land use to ecosystem function in temperate grassy vegetation. Agriculture, Ecosystems and Environment 128:251-258.

McIntyre, S., and S. Lavorel. 2006. A conceptual model of land use effects on the structure and function of herbaceous vegetation. Agriculture, Ecosystems and Environment 2007: $11-21$.

McIntyre, S., T. G. Martin, K. M. Heard, and J. Kinloch. 2005. Plant traits predict impact of invading species: an analyses of herbaceous vegetation in the subtropics. Australian Journal of Botany 53:757-770.

Meer, T. L., T. L. Bell, N. J. Enright, and S. Kasel. 2009. Role of plant functional traits in determining vegetation composition of abandoned grazing land in north-eastern Victoria, Australia. Journal of Vegetation Science 19:515-524.

Milchunas, D. G., and W. K. Lauenroth. 1989. Threedimensional distribution of plant biomass in relation to grazing and topography in the shortgrass steppe. Oikos 55: 82-86.

Milchunas, D. G., and W. K. Lauenroth. 1993. Quantitative effects of grazing on vegetation and soils over a range of environments. Ecological Monographs 63:327-366.

Ohgushi, T. 2005. Herbivore-induced effects through trait change in plants. Annual Review of Ecology, Evolution, and Systematics 36:81-105.

Osnas, J. L. D., J. W. Lichstein, P. B. Reich, and S. W. Pacala. 2013. Global leaf trait relationships: mass, area, and the leaf economic spectrum. Science 340:741-744.

Peeter, P. J. 2002. Correlations between leaf structural traits and the densities of herbivorous insect guilds. Biological Journal of the Linnean Society 77:43-65. 
Pinheiro, J. C., and D. M. Bates. 2000. Mixed-effects models in S and S-plus. Springer Verlag, New York, New York, USA.

Quetier, F., A. Thebault, and S. Lavorel. 2007. Plant traits in a state and transition framework as markers of ecosystem response to land-use change. Ecological Monographs 77: 33-52.

R Development Core Team. 2013. R: language and environment for statistical computing. R Foundation for Statistical Computing, Vienna, Austria. http://www.R-project.org/

Rayment, G. E., and F. R. Higginson. 1992. The Australian handbook of soil and water chemical methods. Inkata Press, Melbourne, Australia.

Risch, A. C., A. G. Haynes, M. D. Busse, F. Filli, and M. Schütz. 2013. The response of soil $\mathrm{CO}_{2}$ fluxes to progressively excluding vertebrate and invertebrate herbivores depends on ecosystem type. Ecosystems 16:1192-1202.

Risch, A. C., M. Schütz, M. L. Vandegehuchte, W. H. Van Der Putten, H. Duyts, U. Raschein, D. J. Gwiazdowicz, M. D. Busse, D. S. Page-Dumroese, and N. Zimmerman. 2015. Aboveground vertebrate and invertebrate impact on net $\mathrm{N}$ mineralization in subalpine grasslands. Ecology 96:3312-3322.

Sbrissa, A. F., A. P. G. da Silva, C. A. Brandao de Carvalho, R. A. Carnevalli, L. F. deMouro Pinto, J. L. Fagundes, and C. G. Silveira Pedreira. 2001. Tiller size/population density compensation in grazed coastcross bermudagrass swards. Scientia Agricola 58:655-665.

Schütz, M., A. C. Risch, G. Achermann, C. Thiel-Egenter, D. S. Page-Dumroese, M. F. Jurgensen, and P. J. Edwards. 2006. Phosphorus translocation by red deer on a subalpine grassland in the Central European Alps. Ecosystems 9:624-633.

Schütz, M., A. C. Risch, E. Leuzinger, B. O. Kruesi, and G. Achermann. 2003. Impact of herbivory by red deer (Cervus elaphus L.) on patterns and processes in subalpine grasslands in the Swiss National Park. Forest Ecology and Management 181:177-188.

Schütz, M., T. Wohlgemuth, B. O. Krüesi, G. Achermann, and H. Gramiger. 2000. Influence of grazing pressure on species richness in subalpine grassland in the Swiss National Park. Nationalpark-Forschung in der Schweiz 89:39-65.

Tilman, D. 1988. Plant strategies and the dynamics and structure of plant communities. Princeton University Press, Princeton, New Jersey, USA.

Utsumi, S., Y. Ando, and T. Miki. 2010a. Linkages among trait-mediated indirect effects: a new framework for the indirect interaction web. Population Ecology 52:485-497.

Utsumi, S., Y. Ando, H. Roininen, J.-I. Takahashi, and T. Ohgushi. 2013. Herbivore community promotes trait evolution in a leaf beetle via induced plant response. Ecology Letters 16:362-370.

Utsumi, S., O. Kishida, and T. Ohgushi. 2010b. Trait-mediated indirect interactions in ecological communities. Population Ecology 52:457-459.

Viola, D. V. V., E. A. Mordecai, A. G. Jaramillo, S. A. Sistla, L. K. Albertson, J. S. Gosnell, B. J. Cardinale, and J. M. Levine. 2010. Competition-defense tradeoffs and the maintenance of plant diversity. Proceedings of the National Academy of Sciences USA 107:17217-17222.

Vitousek, P. M., S. Porder, B. Z. Houlton, and O. A. Chadwick. 2010. Terrestrial phosphorus limitation: mechanisms, implications and nitrogen-phosphorus interactions. Ecological Applications 20:5-15.

Vitousek, P. M., et al. 2002. Toward an ecological understanding of biological nitrogen fixation. Biogeochemistry 57 : $1-45$.

Westoby, M., and I. J. Wright. 2006. Land-plant ecology on the basis of functional traits. Trends in Ecology \& Evolution 21:261-268.

Wilson, P. J., K. Thompson, and J. G. Hodgson. 1999. Specific leaf area and leaf dry matter content as alternative predictors of plant strategies. New Phytologist 143:155-162.

Wright, I. J., et al. 2004. The worldwide leaf economics spectrum. Nature 428:821-827.

Wright, I. J., et al. 2005. Assessing the generality of global leaf trait relationships. New Phytologist 166:485-496.

\section{Data Avallability}

Data available from the Dryad Digital Repository: https://doi.org/10.5061/dryad.10460. 